\title{
Monitoring of Welding Using Laser Diodes
}

\author{
Badr M. Abdullah \\ King Fahd University of Petroleum and Minerals Dhahran, \\ Saudi Arabia
}

\section{Introduction}

For traditional manual welding, the positioning of the welding torch and the selection of the welding parameters are controlled by the operator. Hence, the quality of the resultant weld was determined by the practical skill of the welder and their knowledge of the welding process. For automation and control, a sensor or a vision system is required to detect the various deviations and implement the necessary changes. The overall objective of this system is to provide reliable real-time measurements of the molten weld pool for use with a process controller. The weld pool contains important information about the welding process, which can be used by the process controller to adjust the welding parameters and regulate the weld pool width in order to allow for consistent welds. As welding becomes more complex and operates at higher speeds in more difficult environments, automation of welding become an increasingly attractive option to industry. Defects in welding also need to be detected to ensure efficient, high-quality production. All these needs have led to a growing interest in the use of sensors to provide accurate, robust, real-time monitoring where this cannot be achieved by more traditional testing and inspection techniques. Yet, most of these techniques have concentrated on specific applications and have led to the development of semi-automated welding systems rather than fully automated welding systems. The use of sensors monitoring systems has limited and specific applications. However, the use of vision systems has paved the way for a new direction in weld monitoring. This kind of weld monitoring has not been thoroughly investigated, although it has huge number of applications such as the oil industry.

Techniques based on vision systems have so far been affected by the high expense of the components and are not useful for production systems, in many cases because these sensing systems are either bulky, very expensive to produce and only suitable for specific applications. During the previous study, it was demonstrated that the intense arc light can be successfully eliminated and that a substantial amount of information can be obtained in real time, e.g. metal transfer in TIG welding and weld pool geometry, position and development. However, in this project, the focus is on the use of laser diodes as a source of illumination. In this study, a promising alternative low-cost and compact illumination source is used to illuminate the weld pool area with sufficient power is investigated. This illumination source is based on laser diodes, which are generally more affordable and have characteristics that make them more attractive than the bulky and expensive laser systems.

\section{Weld monitoring overview}

One of the major advantages of using a visual sensing technology to monitor welding operations is the fact that the visual sensor is not touched or interfered with during the 
welding process and visual images of the weld pool contain more abundant and accurate information about the welding dynamics. The main difficulty encountered in vision-based sensing of the weld pool geometry is the strong interference from the arc light across a wide spectrum. A major difficulty with automation of arc welding is the lack of a suitable weld quality sensor. Typical automated welding systems may be capable of controlling only torch position, travel speed, arc voltage and arc current (Boughton et al., 1978)]. However, these variables are generally controlled only according to some pre-determined conditions rather than according the actual weld condition. Many attempts have been made in the past to find a method of sensing weld penetration so that it can be adequately controlled. Weld pool geometric appearance has bee used to measure weld joint penetration (Kovacevic et al., 1996). Chin used infrared thermography from the backside of the weld sheet to make isothermal maps (Chin et al., 1983). Wickle used infrared sensing of arc welding (Wikle \& Kottingam, 2001). Richardson used brightness pyrometry coupled with an axial view torch to measure and control the width of the weld bead (Richardson et al., 1982). Infrared measurements of base metal temperature for online feedback controls were used. However, both arc and electrode radiation interfered very significantly with infrared measurements made at a location on the base metal (Richardson \& Edwards, 1995; Farson et al., 1998). Li developed a theoretical model to relate the arc light radiation to welding parameters (Li \& Zhang, 2000). Other attempts have also been made on ultrasonic technology and chromatic filtering of thermal radiation (Miller et al., 2002; Baik et al., 2000). Other techniques were developed using artificial intelligence based approach for process parameter prediction (Balfour et al., 2000; Luo et al., 2002). Weld pool monitoring for specific applications has also been attempted, e.g. welding of steel pipes, $\mathrm{CO}_{2}$ short circuiting arc welding and laser welding of thin sheet metals (Ancona et al., 2004; Sun et al., 2006; Frazer et al., 2002; Du et al., 2000).

The continuous reduction in the cost of cameras and illumination systems over the last five years has allowed vision systems to be increasingly used as sensors to extract information about the weld pool. Intensive research has been done to develop a vision system, which can be used for direct weld pool viewing (Chen et al., 2003; Wu et al., 2000). Some researchers used both camera and an illumination source in their systems, while others just used a camera without any illumination. Y. M. Zhang and R. Kovacevic used a polar coordinate model to characterise the weld pool geometrically. A neural network algorithm was developed to identify the welding parameters in real-time. Although they used pulsed laser illumination to illuminate the weld pool, interference from the arc light is clearly visible in the images obtained (Zhang et al., 1996). L Hong used a high speed camera and a high power pulsed laser for illumination. A LaserStrobe vision system and a neurofuzzy control system were used for arc welding process control (Hong et al., 2000). Other research used only cameras to observe the weld pool without the use of any illumination sources. These vision systems lacked proper illumination, and hence, the images appeared either too dark when the shutter time of the camera is decreased or too bright when the shutter time is increased. For example, K. Y. Bae used a vision system for both seam tracking and weld pool control. A CCD camera was used in the vision system to capture images of the weld pool area, but again the interference from the arc light proved a major problem and the images obtained suffered greatly from the presence of arc light (Bae et al., 2000). C. S. Wu used a CCD camera combined with a light filter to form a vision sensing system. Since no illumination was used, the weld pool images appeared too dark with very bright areas in the centre due to the intense arc light (Wu et al., 2003).

During the past few years more studies have emerged using more complex techniques. A study by Huang and Kovacevic used acoustic signals for online monitoring of weld depth. 
Acoustic signals generated during the laser welding process of high-strength steel DP980 were recorded and analysed. A microphone was used to acquire the acoustic signals. A spectral subtraction method was used to reduce the noise in the acoustic signals, and a Welch-Bartlett power spectrum density estimation method was used to analyse the frequency characteristics of the acoustic signals. The study showed that good welds can be distinguished from bad weld and that the acquired signal can be used to control weld depth (Huang \& Kovacevic, 2009). Another study used a multiple of sensors to monitor weld penetration. Infrared, ultraviolet and sound sensors were used simultaneously. Infrared sensors were used to detect heat radiation, ultraviolet sensors were used to measure optical radiation and sound sensors were used to measure welding penetration state (Zhang et al., 2008; Allende et al., 2008). Another spectroscopic technique based on the acquisition of the optical spectra emitted from the laser generated plasma plume and their use to implement an on-line algorithm for both the calculation of the plasma electron temperature and the analysis of the correlations between selected spectral lines (Sibillano et al., 2009). Song and Zhang utilized the reflection property of the weld pool surface. In their system, a dot-matrix pattern of structured laser light was projected onto the specular weld pool surface and its reflection was imaged on a self-designed imaging plane. Then the distorted reflected image (pattern) was captured and processed. Based on the obtained information, two reconstruction schemes named interpolation reconstruction scheme (IRS) and extrapolation reconstruction scheme (ERS) were used in order to rebuild the three dimensional weld pool surface off-line (Song \& Zhang, 2008). Arc sound has been found to be strongly related to process parameters and weld quality (Arata et al., 1980; Futamat, 1983; Pal et al., 2010). Welding arc light can be seen as a signal carrying essential information about the welding process. The information contained in the signal can be exploited in the monitoring of the welding process. A recent study by the Institute of Welding in Poland employed this idea for monitoring MIG welding (Weglowski, 2009). A review was proposed by TWI to review the available literature on sensor systems for the top-face control of weld pool penetration in arc and laser welding, with a view to developing a commercial system for the top-face control of weld penetration (Anderson, 1997). The review concluded that there is currently no system commercially available which satisfies all the requirements of the ideal system, although some sensors have been successfully applied in specific applications. The range of application and accuracy of control of these systems can be summarized as follows:

1. Ultrasonic techniques are only suitable for plate thickness of less than $2 \mathrm{~mm}$ or greater than $10 \mathrm{~mm}$. The accuracy of control needs to be improved before they can be used for practical applications.

2. Acoustic emission monitoring will function independently of welding position, process and joint type, but has still to be effectively demonstrated.

3. Weld pool sag sensing is limited to the flat position, butt welds and requires a highly accurate power source.

4. Weld pool oscillation frequency monitoring by optical systems can only be used for full penetration butt welds, and requires the back surface of the weld to be free of oxide and contamination.

5. Direct weld pool viewing functions independently of position, process and joint type, but requires accurate control of component thickness and joint fit-up.

6. Thermal sensing functions independently of position, process and joint type, but its accuracy is reduced by variations in the surface emissivity of the component material. 


\section{Basis of vision system}

\subsection{Welding spectra}

Arc light emissions have the potential as a welding information source. The emission changes with weld parameters, these parameters include current, voltage, electrode diameter and type, and shielding gas. Some researchers have applied welding spectra for weld monitoring (Zackenhouse \& Hrdt, 1983; Sorensen \& Eagar, 1990; Sforza \& de Blasiis, 2002). In these studies, it was shown that the emission spectra can be used to detect changes in the welding arc. Other studies including this one incorporated welding spectra to enhance the image quality of the weld pool. Further studies investigated the possibility of sensing welding behaviours based on arc light (Li \& Zhang, 2000). In another research work, an arc light sensor was used to monitor the droplet transfer mode in GMAW (Madigan et al., 1989). To determine the optimum spectral window to operate at, welding trials were carried out on stainless steel with argon and helium as shielding gasses. An optical spectrum analyser with a wavelength range from $350 \mathrm{~nm}$ to $1750 \mathrm{~nm}$ was used to obtain the spectra of TIG welding shown in Fig. 1.

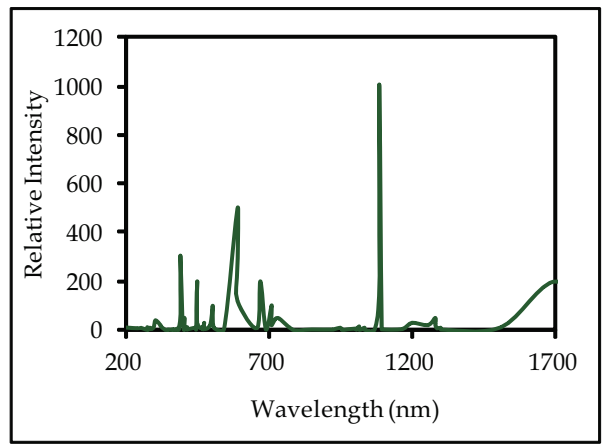

a. Argon spectrum

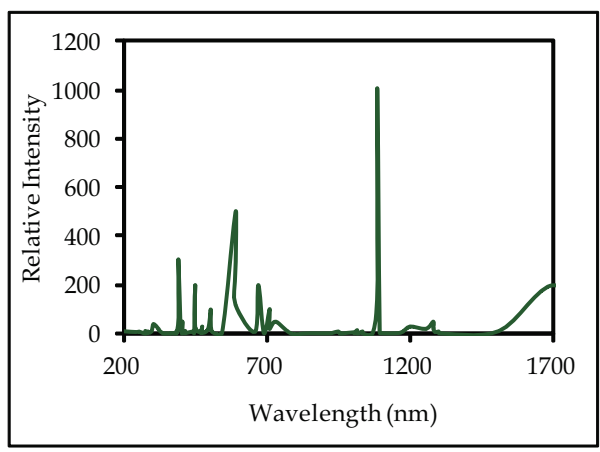

c. TIG welding on stainless steel, $100 \%$ argon, 150A

Fig. 1. Welding spectra

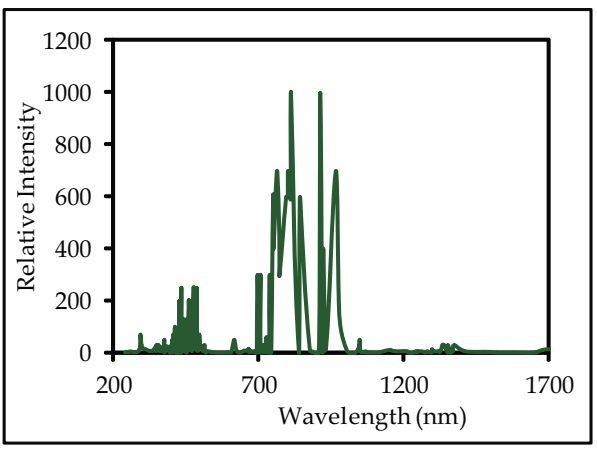

b. Helium spectrum

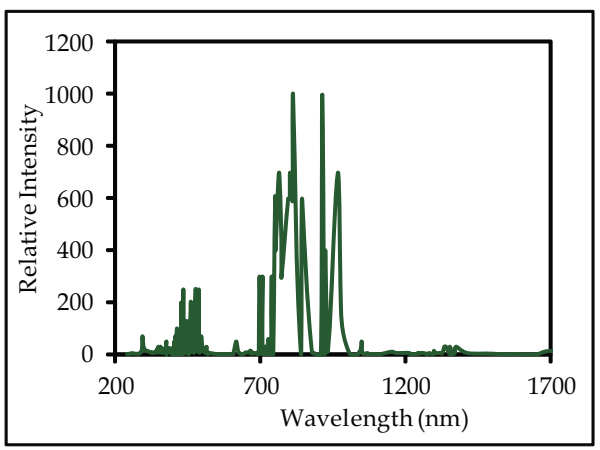

d. TIG welding on stainless steel, $100 \%$ argon, 150A 
Strong emission lines from the shielding gas can be seen at different wavelengths in each of the two spectral distributions of shielding gases shown. Strong emission lines appear at around $800 \mathrm{~nm}$ in the spectral distribution of argon, whilst with helium, strong lines appear at around $400 \mathrm{~nm}$ to $600 \mathrm{~nm}$ with the exception of a very strong line at around $1100 \mathrm{~nm}$. It has also been found from this study that most of the strong emission lines appear at all current settings on the same base material and shielding gas but with varying relative intensities. Higher current settings result in higher relative intensities, and lower current settings result in lower relative intensities for all shielding gases and base materials. When helium is used, the relative intensity across the spectrum is greatly reduced especially at around $800 \mathrm{~nm}$, where it was at its peak with argon and the argon mixture. Some strong emission lines are still abundant at around 400nm but with greatly reduced intensities. It has also been found that the base metal also affect the emission intensities in both shielding gases. The strong lines that appeared at $800 \mathrm{~nm}$ disappeared when mild steel is used. However, intensity peaks have shifted towards the UV region. Since arc light is abundant in the visible and UV regions and weld pool emissions are abundant in the IR region, the optimum spectral window to operate at is in the IR region. Therefore, taking into consideration the limitations of the camera above $1000 \mathrm{~nm}$, the best wavelength to operate at is around $800 \mathrm{~nm}-950 \mathrm{~nm}$.

\subsection{Spectral filtering}

During arc welding arc light is emitted over a range of wavelengths. Only parts of the wavelengths will be detected by a given camera. A typical spectral response range for a standard visible light camera is $350 \mathrm{~nm}-850 \mathrm{~nm}$, falling sharply outside this range. However, laser diode illumination is at a very specific wavelength, with a typical wavelength of a few nanometres. This is illustrated in Fig. 2, which shows how the light from a laser source might compare with the arc light. If we illuminate the bright welding area with a laser diode source and place a narrow band pass filter with the same wavelength as the laser diode in front of the camera, then only the laser diode light will pass with a fraction of the arc light. The result is a much-attenuated arc light with little effect on the laser diode light as illustrated.

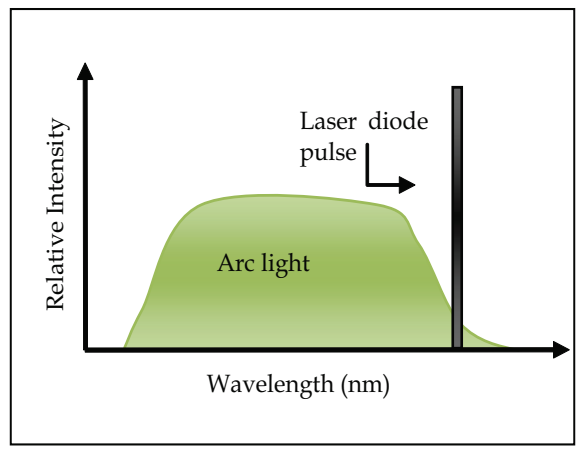

a. Pre-spectral filtering

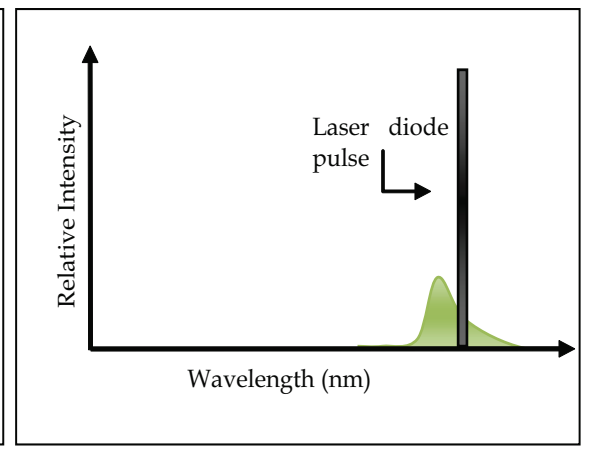

b. Post-spectral filtering

Fig. 2. Effect of spectral filtering on light absorbed by the camera 


\subsection{Temporal filtering}

Spectral filtering attenuates the arc light but it is not enough alone to totally eliminate the arc light. Temporal filtering provides further arc light reduction without attenuating the laser diode light as long as the pulse width remains shorter than the camera's shutter exposure time. More unwanted arc light will be captured if a longer exposure time is used. This has no effect on how much of the desired laser diode light is captured as long as the pulse width remains shorter than the exposure time. This is always the case for most laser sources which have pulse width durations in the nanosecond region, whereas the camera exposure time is normally in the microsecond region. Laser light will only be attenuated if the pulse width is greater than the exposure time of the camera or if the laser is a continuous wave laser rather than a pulsed laser. The reduction of the arc light when a shorter exposure time is used is illustrated in Fig. 3.

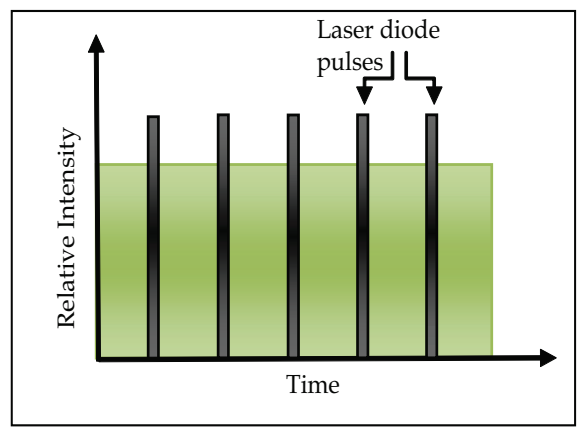

a. Pre-temporal filtering

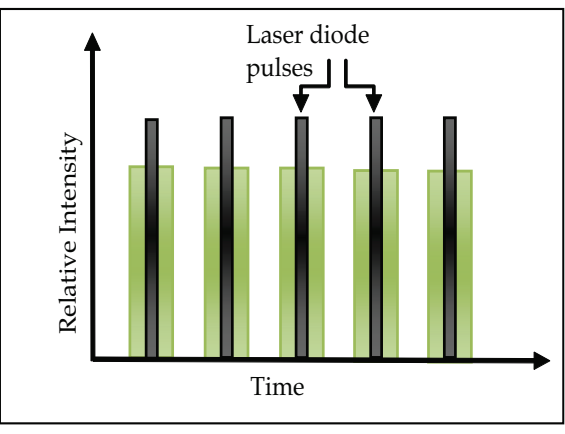

b. Post-temporal filtering

Fig. 3. Effect of temporal filtering on light absorbed by the camera

\subsection{Camera-laser synchronisation}

\subsubsection{Trigger methods}

The use of triggering is a powerful feature to the capabilities of image acquisition systems. It gives us the ability to efficiently capture a short duration and high speed events by eliminating the need to continuously acquire images while waiting for the event to occur. An external trigger is an event that starts an exposure. The trigger signal is either generated on the frame grabber (soft-trigger) or comes from an external trigger between the laser diode and the camera is essential for obtaining high quality images without the need for a high power illumination system.

Figure 4 shows four synchronisation methods that can be used to capture the laser pulse. In Fig. $4 \mathrm{a}$, the camera is driving the laser. A pulsed output from the back of the camera is connected to the laser external input. This guarantees a good synchronisation. However a pulse delay is introduced which can be overcome by delaying the camera strobe signal. In Fig. $4 \mathrm{~b}$, the laser is driving the camera. The external output of the laser device is connected to the external trigger input of the camera. This will also introduce a delay to the camera shutter that can be overcome by introducing a pulse delay. Both the camera 
and the laser can be driven by an external master-triggering unit which consists of either one trigger source or two triggering sources with one of the trigger sources acting as the master trigger and the other as a slave so that a delay can be introduced as shown in Fig. 4c. The frame rate, laser diode frequency and timing of the system can be controlled when connected to a pulse generator. The fourth method is used mainly when using a continuous wave laser as an illumination source as shown in Fig. 4d. Both the camera and the laser are free running and are independently controlled. The idea is to capture as much as possible of the CW laser power, which can be achieved by adjusting the exposure time of the camera.

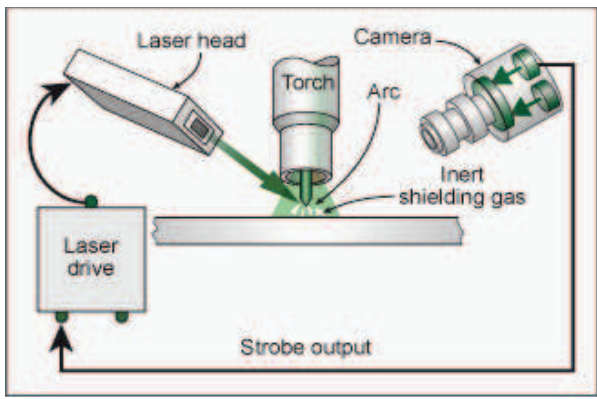

a. Camera as master

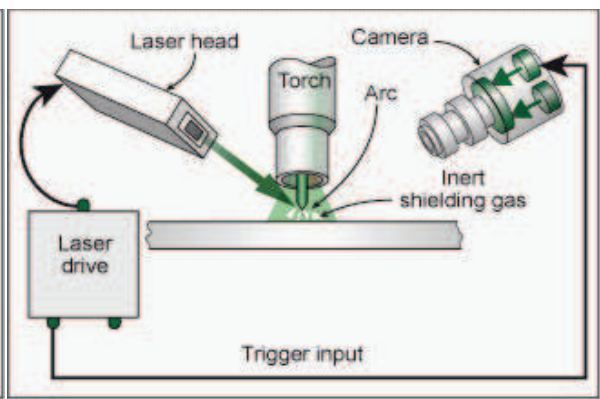

b. Laser as master

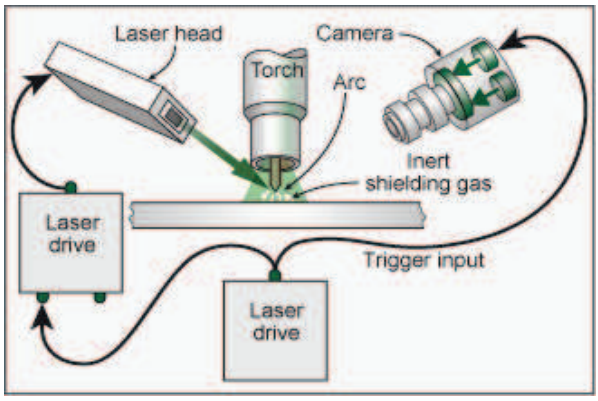

c. Laser and camera driven by an external driver

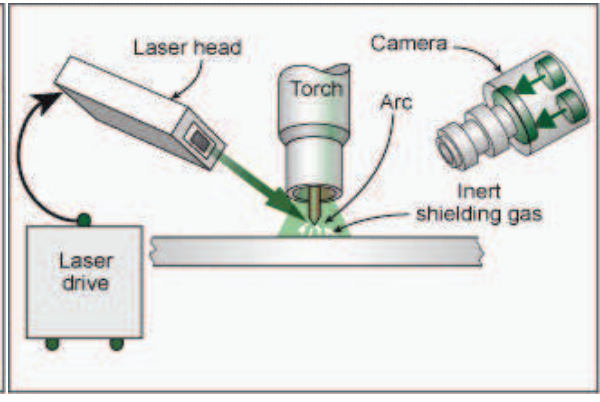

d. Laser and camera independently driven

Fig. 4. Laser camera synchronisation methods

\section{Light capturing}

The light source can either be mounted on the same side as the camera i.e. backward reflection or opposite the camera i.e. forward reflection as shown in Fig. 5. More light is reflected to the camera when the laser is on the opposite side. Hence, less laser energy is required. However, uneven reflection from the weld pool occurs. Varying the angle between the laser beam and the work-piece can improve this. On the other hand, mounting the light source on the same side as the camera gives natural lighting with little glare but requires more laser energy as most of the laser light reflects away from the camera. 


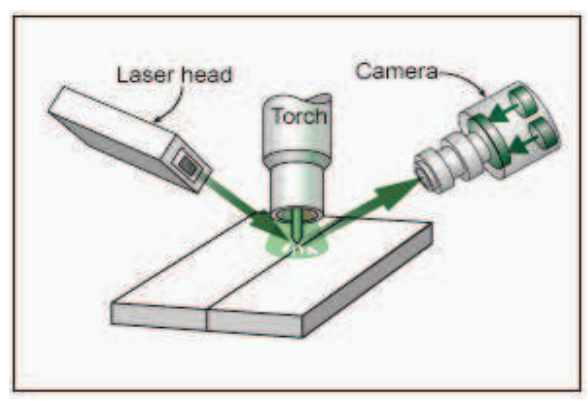

Forward reflection

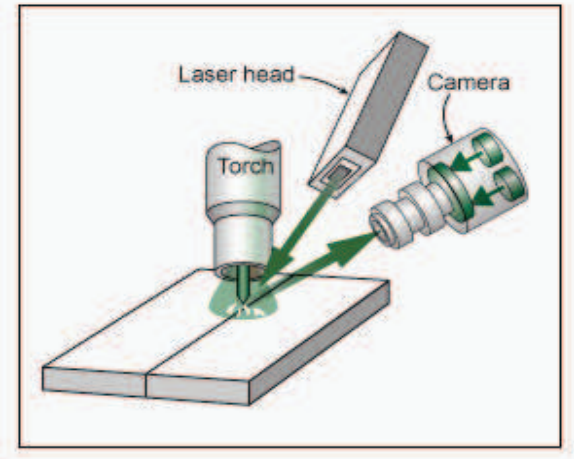

Backward reflection

Fig. 5. Light capturing methods

\section{Laser diode vs. LED}

Illumination technology plays a major role in the design of vision systems, especially for industrial applications where real-time processing is a crucial requirement. The region of interest can be made significantly clear by the proper choice of lighting techniques.

There are five types of illumination that are commonly used for machine vision;

- Halogen (using fibre optic light guides)

- Incandescent

- Fluorescent tube technology

- LEDs

- Lasers

Halogen, incandescent and fluorescent lighting is poor for this type of application. They have very limited use in machine vision applications which require pulsing at short widths and suffer from inherent flicker and can not be easily controlled to maximise their intensity.

Practically, LED technology now provides the most appropriate solution for most machine vision applications. This is because LEDs produce a relatively high light intensity at a relatively low cost compared to halogen, incandescent and fluorescent technologies. However, applications such as real-time weld pool monitoring require much more power than a commercial LED can afford and require narrow bandwidth and very short pulsing widths. In this section we compare the two main rivals, LEDs and laser diodes.

\subsection{Light emitting diodes}

The structure of an LED consists of a chip, made of semiconductor material, impregnated with impurities to create a junction. The semiconductor diode chip is mounted in the reflector cup of a lead frame that is connected to electrical (wire bond) wires, and then encased in a solid epoxy lens. Electrical current flows easily from the positive anode to the negative cathode of the junction but not in the reverse direction. Electrical charge-carriers, electrons, and electron holes flow into the junction from electrodes with different voltages. 
When an electron meets a hole, it falls into a lower energy level and releases light energy in the form of a photon. In other words, when electrical current passes through them, LED chips illuminate, creating fast direct light that lasts much longer, about 50 times as long, and burns much brighter than conventional incandescent light bulbs. LEDs emit light when energy levels change in the semiconductor diode. This shift in energy generates photons, some of which are emitted as light. The specific wavelength of the light depends on the difference in energy levels as well as the type of semiconductor material used to form the LED chip. LEDs are made from compound semiconductor materials such as gallium arsenide (GaAs), gallium phosphide $(\mathrm{GaP})$, gallium arsenide-phosphide (GaAsP), silicon carbide $(\mathrm{SiC})$ and gallium indium nitride $(\mathrm{GaInN})$. The material used in the construction of an LED's PN junction determines the energy of the emitted photons and hence the colour.

\subsection{Laser diodes}

Laser diodes are complex semiconductors that convert an electrical current flowing through a P-N junction into light. Electrons and holes combine, releasing the energy as photons. This process can be spontaneous, but can also be stimulated by incident photons leading to amplification. The conversion process is fairly efficient in that it generates little heat in the process compared to incandescent lights. Laser diodes are normally built as edge emitting lasers, where the laser cavity is formed by coated or uncoated end facets (cleaved edges) of the semiconductor wafer. They are often based on a double hetero-structure, which restricts the generated carriers to a narrow region and at the same time serves as a wave guide for the optical field. This arrangement leads to a lower threshold pump power and better efficiency. The active region also often contains quantum wells or quantum dots. Some modern kinds of laser diodes are of the surface emitting type, where the emission direction is perpendicular to the wafer surface. Laser diodes are typically constructed of GaAlAs (gallium aluminium arsenide) for short-wavelength devices. Long-wavelength devices generally incorporate InGaAsP (indium gallium arsenide phosphide).

\subsection{Main characteristics}

Table 1 offers a quick comparison of some of the main characteristics for laser diodes and LEDs.

\begin{tabular}{|c|c|c|}
\hline Characteristic & LED Diodes & Laser Diodes \\
\hline Current & Up to $2.5 \mathrm{~A}$ & Up to $40 \mathrm{~A}$ \\
\hline Power & Less than $2.5 \mathrm{~W}$ & Up to $250 \mathrm{~W}$ \\
\hline Emission pattern & Larger than $40^{\circ}$ & $10^{\circ}$ to $25^{\circ}$ \\
\hline Wavelengths available & $0.66 \mu \mathrm{m}$ to $1.65 \mu \mathrm{m}$ & $0.78 \mu$ to $1.65 \mu \mathrm{m}$ \\
\hline Spectral width & Wide (20nm -190nm FWHM) & Narrow (3nm to $10 \mathrm{~nm}$ FWHM) \\
\hline Cost & Less than $£ 2$ & $£ 15$ to $£ 400$ \\
\hline Pulse width & 100us (minimum) & $40 \mathrm{~ns}$ (minimum) \\
\hline
\end{tabular}

Table 1. Main characteristics of laser diodes and LEDs

\subsection{Spectral width}

Ideally, all the light emitted from a laser diode would be at the peak wavelength, but in practice the light is emitted in a range of wavelengths centred at the peak wavelength. This 
range is called the spectral width of the source. Laser diodes have very narrow spectral width ranging from $3 \mathrm{~nm}$ to $10 \mathrm{~nm}$ but not as narrow as other commercial laser systems like the Nd:YAG laser, which normally have very narrow spectral width ranging from $0.00001 \mathrm{~nm}$ to $1 \mathrm{~nm}$. Meanwhile, LEDs have a wider spectral width, typically over $20 \mathrm{~nm}$. Spectral width is a crucial factor for the vision system. Wide spectral width means a wider band pass filter will be used and hence more the unwanted arc light will be captured by the camera.

Most laser diode wavelengths emit in the near infrared spectral region, but some can emit in the visible or infrared regions. However, laser diode wavelength is being pushed further and further into the visible spectrum. The latest generation of Visible Laser Diodes (VLD's) operate at or near $635 \mathrm{~nm}$ which is highly visible to the human eye. VLD's in the range from $635 \mathrm{~nm}$ to $685 \mathrm{~nm}$ are replacing the traditional HeNe laser in many commercial products for good reasons: lower cost, compact size, and superior long-term reliability. Another intrinsic benefit, laser diodes are generally better suited for battery operated devices and other low voltage applications. LEDs are available in both visible and infrared wavelengths. Infrared LEDs reach wavelengths of $830 \mathrm{~nm}$ to $940 \mathrm{~nm}$. Visible colours include red, yellow, orange, amber, green, blue/green, blue, and white. These fall into the spectral wavelength region of $400 \mathrm{~nm}$ to $700 \mathrm{~nm}$. The coloured light of a LED is determined exclusively by the semiconductor compound used to make the LED chip and independent of the epoxy lens colour. The FWHM bandwidth of a typical LED ranges from 20nm to 190nm as shown in Fig. 6.

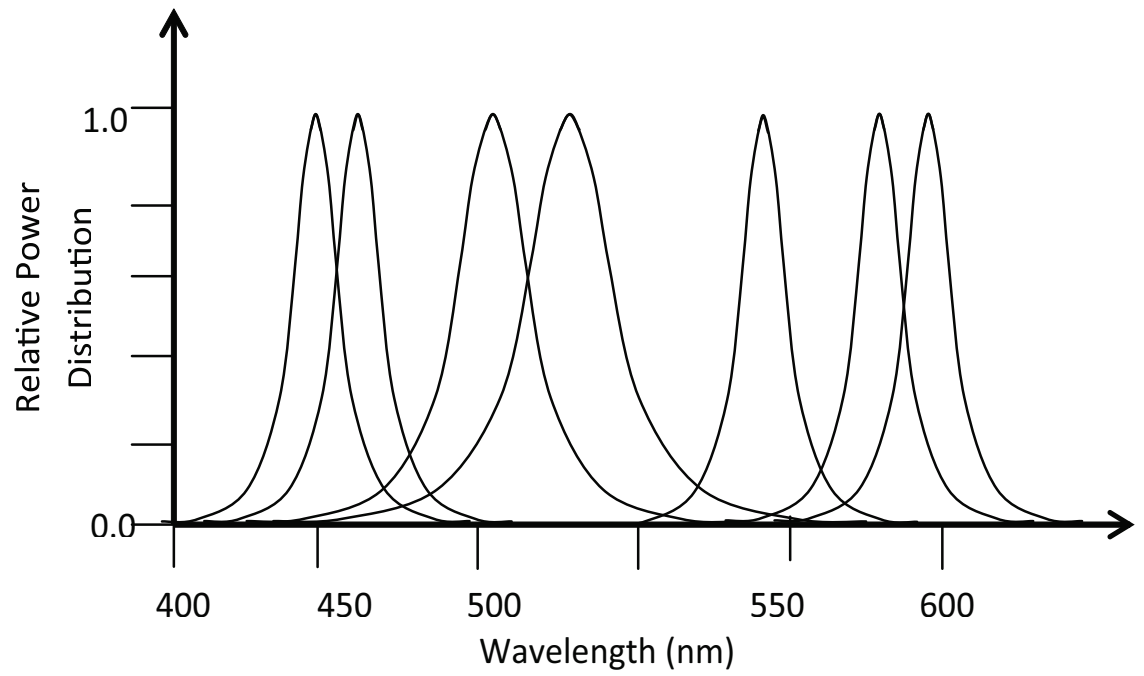

Fig. 6. Bandwidth of typical commercial LEDs

\subsection{Pulse width}

Laser diodes can be pulsed at very short pulse widths typically around 40ns - 100ns (minimum). The pulse width can be increased to around 10us as long as the duty cycle is kept low and lower currents are used. Meanwhile, LEDs have a much longer pulse width, typically around 100us. Pulsing laser diodes at very short pulse widths also means that they can be overdriven to obtain more power as long as the duty cycle is not exceeded. 
There are two main reasons for the use of pulsed operation with LED illuminators intended for use in machine vision applications. The first is to freeze action to acquire an image with the camera shutter. The second is to increase the effective brightness of the illuminator during the pulse by using a higher pulse current than the CW rating, since the luminance is proportional to current. As the pulse width (i.e. when the LED is on) decreases, more current can be used to drive the LED, and therefore more power is produced. The duty cycle also decreases with a decreasing pulse width. If low duty cycles are combined with short pulse widths, so that the junction temperature of the LED is kept close to ambient, then the effective operating lifetimes can be extended.

\subsection{Emission pattern}

The pattern of emitted light affects the amount of light that can be either directed onto the welding area either by coupling it into an optical fibre or by placing it close enough to the weld scene and focussing the beam without fibre coupling.

Figure 7 illustrates the emission pattern of a laser diode and LEDs. The angle at which light comes out from the laser diode is much smaller than that of the LEDs as shown below. Since the weld pool area to be illuminated is small, an illumination source with a narrow emission pattern is needed.
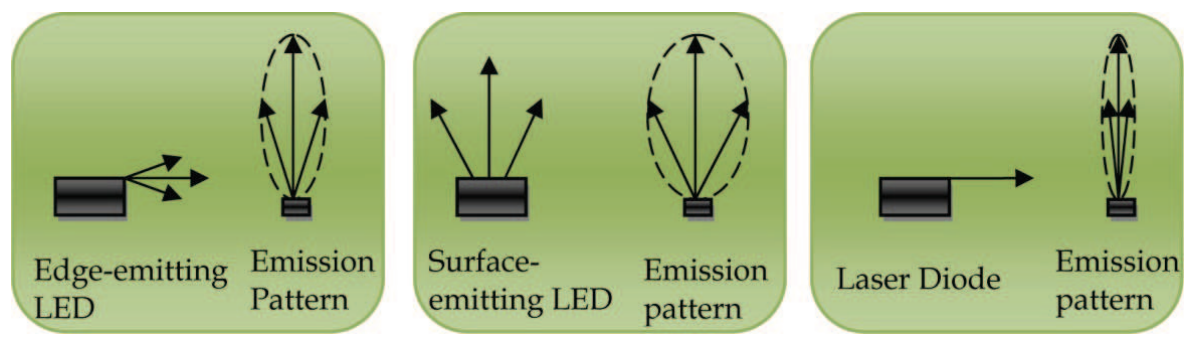

Fig. 7. Emission patterns for LEDs and laser diodes

There are two types of LEDs, edge emitters and surface emitters. Edge emitters are more complex and expensive devices, but offer high output power levels and high speed performance. The output power is high because the emitting spot is very small, typically 30 $50 \mu \mathrm{m}$, allowing good coupling efficiency to similarly sized optical fibres. Edge emitters also have relatively narrow emission spectra. The full-width half-maximum (FWHM) is typically about $7 \%$ of the central wavelength. Another variant of the edge emitter is the super-radiant LED. These devices are a cross between a conventional LED and a laser diode. They usually have a very high power density and possess some internal optical gain like a laser diode, but the optical output is still incoherent, unlike a laser diode. Super-radiant LEDs have very narrow emission spectra, typically $1-2 \%$ of the central wavelength and offer power levels rivalling a laser diode.

Surface emitters on the other hand have a comparatively simple structure and are relatively inexpensive. They offer low to moderate output power levels, and are capable of low to moderate operating speeds. The total LED chip optical output power is as high or higher than the edge emitting LED, but the emitting area is large, causing poor coupling efficiency to the optical fibre. Adding to the coupling efficiency deficit is the fact that surface emitting 
LEDs are almost perfect lambertian emitters. This means that they emit light in all directions. Thus, very little of the total light goes in the required direction.

\subsection{Power}

In general, laser diodes are a lot more powerful than LEDs. Laser diodes can be driven with more current and hence an increased output power. For example the Osram SPL PL90_3 can be pulsed with a maximum pulse current of $40 \mathrm{~A}$, which produces a peak power of up to 90W. Whereas, LEDs can only be pulsed at currents much less than $40 \mathrm{~A}$ and can only produce a few watts.

\subsection{Luminous efficacy}

Luminous efficacy is the ratio between the total luminous flux emitted by a device and the total electrical power consumed by it. It is a measure of the efficiency of the device with the output adjusted to account for the spectral response curve (luminosity function). When expressed in dimensionless form this value may be called luminous efficiency. Luminous efficiency is a measure of the optical power produced by the source to the actual rated electrical power. The radiant power can be found by dividing the total lumens produced by the luminosity function. For example, a $100 \mathrm{~W}$ tungsten incandescent light source with a luminous efficacy of 17.5 lumens/watt has a total radiant power of $2.56 \mathrm{~W}$ and a luminous efficiency of $2.56 \%$.

The radiant power is the total radiated power in watts which is also called radiant flux. This power must be factored by the sensitivity of the human eye to determine luminous flux in lumens. Today's high power LEDs operating at $1 \mathrm{~W}$ or more deliver $50-601 \mathrm{~m}$, enabling just 50 LEDs to produce the same light output as a $3000 \mathrm{~lm}$ fluorescent tube. At the same time, luminous efficacy has risen to more than $60 \mathrm{~lm} / \mathrm{W}$, which far surpasses the performance of incandescent bulbs and is fast approaching the energy efficiency of fluorescent lighting. As a result, high-power LED manufacturers are now working to develop products addressing the general illumination market, which is currently valued at around $£ 7$ billion. However, real success in the mainstream lighting market will require manufacturers to reduce the price of LEDs, while continuing to deliver steady improvements in the device's luminous efficacy and total lumen output.

\section{System design}

The systems described below are designed and fabricated based on two types of laser diodes, the first system is based on the Osram SPL PL90_3 high power laser diode and the second system is based on the Osram SPL LL90_3 high power laser diode.

\subsection{SPL PL90_3}

The illumination system is made of a cluster of low-cost nano-stack InGaAs/GaAs pulsed laser diodes. Each laser diode is stacked in a plastic package with a maximum peak output power of $90 \mathrm{~W}$ and a typical output power of $75 \mathrm{~W}$ per diode. Each individual laser diode is stacked with three emitters with a laser aperture of $200 \mu \mathrm{m} \times 10 \mu \mathrm{m}$. The maximum power is achieved when the diode is driven by a pulse width of 100ns (FWHM) with a maximum 
forward current of $40 \mathrm{~A}$. The pulse width can be increased to $1 \mu$ s or even $10 \mu$ s with a reduced forward current. The diode was tested with a reduced current of $20 \mathrm{~A}$ and a pulse width of $1 \mu \mathrm{s}$, an optical power output of $43 \mathrm{~W}$ was achieved. The wavelength of the laser diode is $905 \mathrm{~nm}$ and its spectral width is $7 \mathrm{~nm}$ (FWHM).

\subsection{Beam profile}

The photo detector circuit shown in Fig. 8 is used to obtain the beam profile of the laser diode. The light output beam from the laser diode is detected by the photo diode and converted into voltage by the photo detector circuit. Fig. 9a shows the relative intensity output against the range when the horizontal and vertical displacements are kept at zero. Meanwhile, Fig. 9b shows the relative intensity against horizontal displacement at different range distances. From the beam profile results, we can conclude that the emission pattern of the laser diode is narrow, and hence, it is possible to use a cluster of laser diodes for illumination without the need to deliver the optical output to the weld pool via optical coupling.

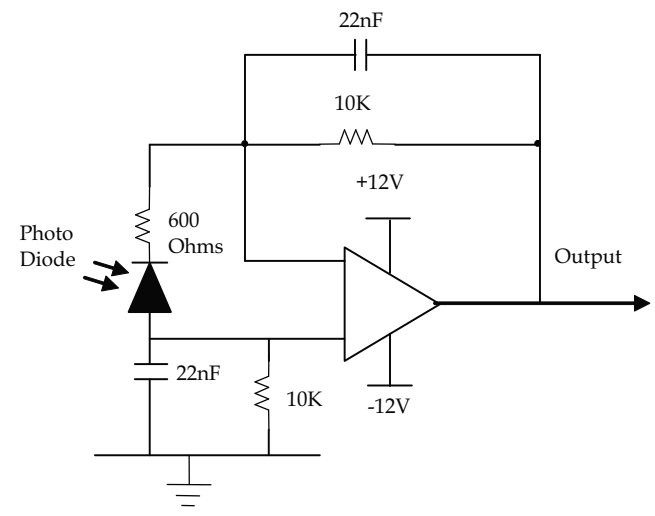

Fig. 8. Photo detector circuit

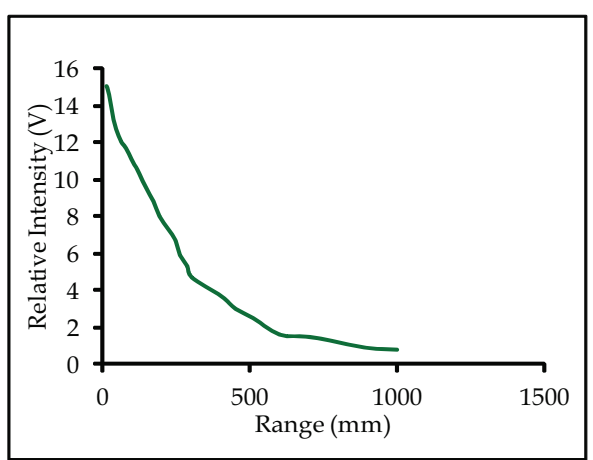

a. Relative intensity vs. range, vertical and horizontal distances are kept at zero

Fig. 9. Laser diode beam profile

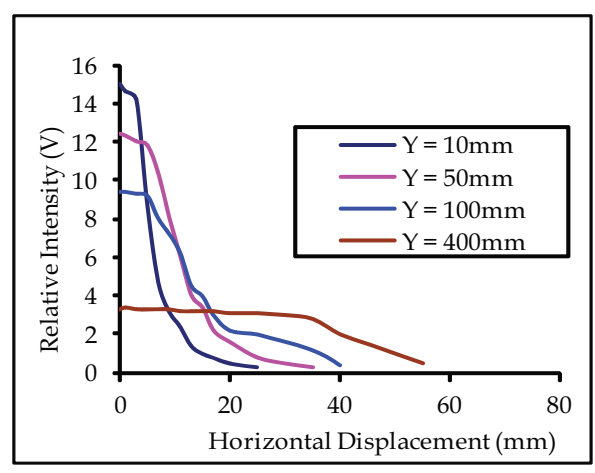

b. Relative intensity vs. horizontal displacement 


\subsection{Driver circuits}

The circuit shown in Fig. 10 is constructed using N-Channel enhancement mode MOSFET. This MOSFET is designed to minimize on-state resistance, which is $0.01 \mathrm{Ohm}$ for this MOSFET, and provide superior switching performance and withstand high current pulse in the avalanche mode. A MOSFET driver is also used to rectify the trigger signal.

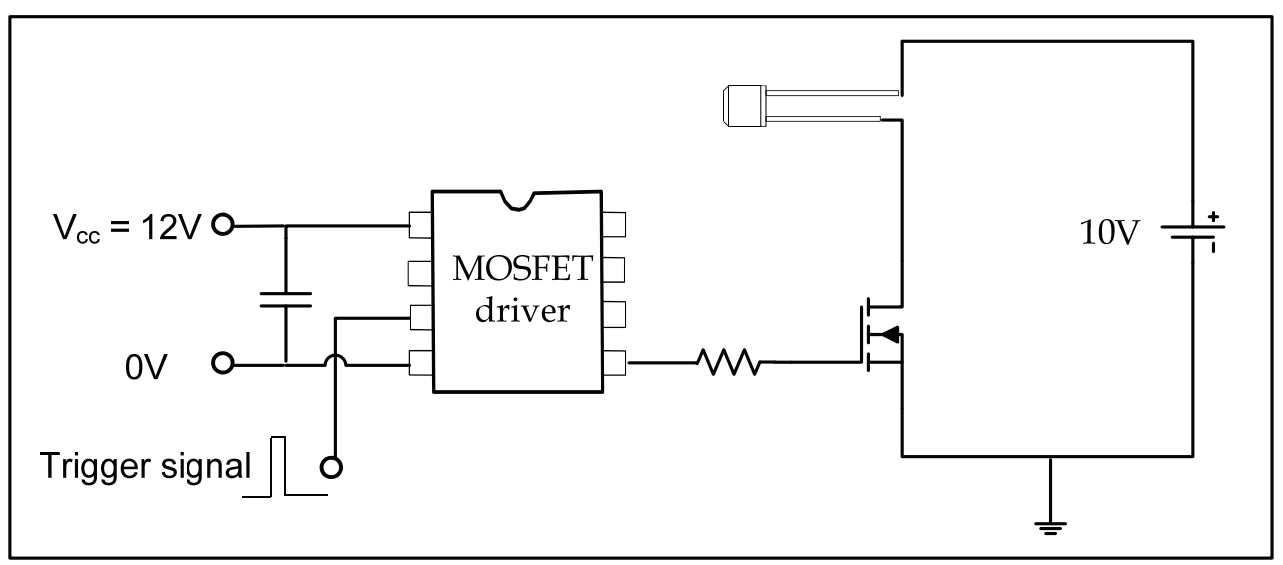

Fig. 10. Schematic diagram of a laser diode driver using a MOSFET as switch

\subsection{SPL LL90_3}

This system is constructed from a low-cost high power laser diode, Osram SPL LL90_3, with integrated driver stage for pulse control and a maximum peak output power of $80 \mathrm{~W}$. The SPL LL90_3 is a hybrid laser module with a lasing wavelength of 905nm. It also contains two capacitors and a MOSFET, which act as a driver stage. The two capacitors are connected in parallel to sum their individual capacitance of $47 \mathrm{nF}$. The capacitors are charged using a constant DC voltage. Each time the gate of the MOSFET is triggered, the capacitors are uncharged via the laser chip leading to a short and high amplitude current pulse. Each individual laser diode is stacked with three emitters with a laser aperture of $200 \mu \mathrm{m} \times 10 \mu \mathrm{m}$. The maximum power is achieved when the diode is driven by a pulse width of $40 \mathrm{~ns}$. The pulse width can be increased to $1 \mu \mathrm{s}$ or even $10 \mu$ s with a reduced forward current.

\subsection{Driver circuit}

In principle the width of the laser pulse is determined by the value of the capacitors inside the plastic package and the pulse width of the MOSFET trigger (gate) signal. The maximum pulse width is 30ns. By increasing the trigger pulse widths beyond 30ns, the FWHM width of the optical pulse and the peak power remain constant but the pulse energy increases. To obtain short optical pulses, the MOSFET gate has to be charged very fast. The MOSFET has a gate capacitance of $300 \mathrm{pF}$. To obtain the required gate-source threshold voltage of $5 \mathrm{~V}$ the gate must be charged with about $7 \mathrm{nA}$ within several 
nanoseconds. Therefore a pulsed trigger current of about $1 \mathrm{~A}$ is required. Such a signal can be generated by a high speed power MOSFET driver IC which itself is triggered by a TTL level voltage signal.

Figure 11 shows the block diagram of the SPL LL90_3 together with the MOSFET driver. The MOSFET inside the hybrid package is the Infineon BSP318S. To operate the SPL LL90_3, two DC voltages are needed namely the supply voltage $V_{C C}$ for the MOSFET driver IC and the charge voltage $V_{C}$ for charging the capacitors. The charging resistor determines the charging current and therefore the time necessary to charge the capacitors i.e. the maximum lasing repetition rate. Problems that can occur are CMOS latch-up, overvoltage spikes, insufficient overdrive and thermal overload. These phenomena can be prevented by using bypassing capacitors and by using clamping schottky diodes and external resistors.

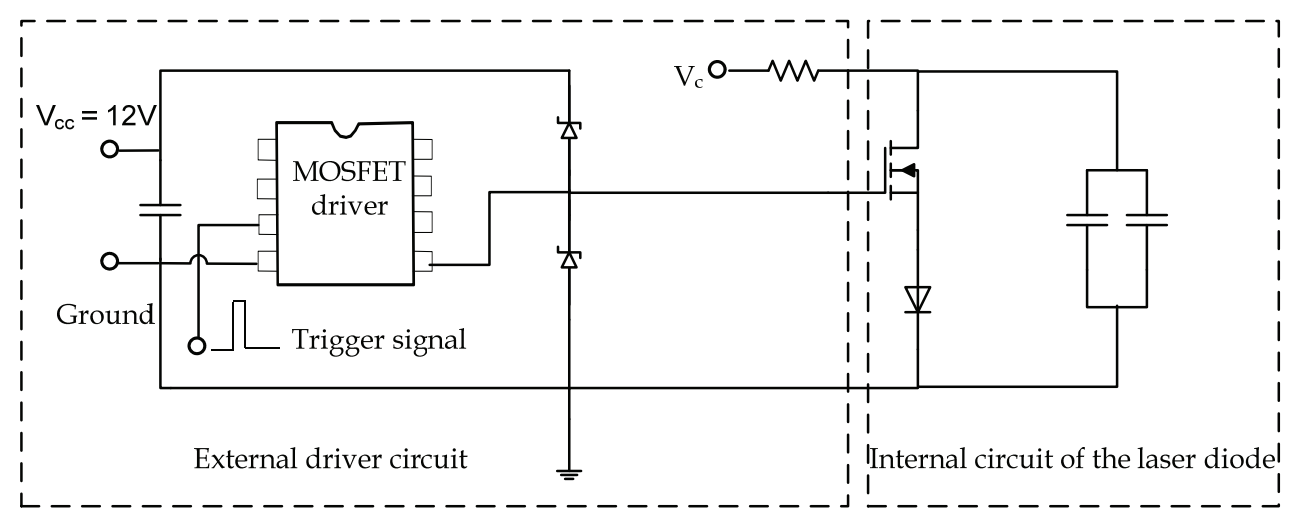

Fig. 11. Schematic of driver circuit of the SPL LL90_3 laser diode

\section{Results}

Figure 12a and Figure 12b show the images obtained using the low-cost Osram SPL PL90_3 laser diode system (type 1) as an illumination source with an emission wavelength of $905 \mathrm{~nm}$. Two diodes were used at a pulse width of 5 us and a duty cycle of $0.01 \%$. Diodes are placed $20 \mathrm{~cm}$ away from the weld pool.

Figure 13a and Figure 13b show the images obtained using the low-cost Osram SPL LL90_3 laser diode system (type 2) as an illumination source with an emission wavelength of $905 \mathrm{~nm}$. The arc light is almost totally eliminated by the use of spectral and temporal filtering and the weld pool area is illuminated by only two laser diodes with an approximate peak power of $150 \mathrm{~W}$. Using more laser diodes will evenly illuminate the weld pool area and produce better images.

Figure 14a shows an image with arc the arc light totally eliminated. However, the image suffers from uneven distribution of illumination on the weld scene. This can be solved by several methods, e.g. using more diodes to illuminate the dark area, spreading the light across the weld pool, varying the angle at which light is focussed onto the weld pool or by relocating the illumination source. Figure $14 \mathrm{~b}$ shows an arc without any weld pool illumination. This 
emphasises the importance of the illumination source. Almost no information can be extracted about the welding process and the image is totally black as the arc light is eliminated by the filtering techniques employed. Figure 14c shows an arc with laser diode illumination. Two SPL PL90_3 diodes are used to obtain this image at a pulse width of 5us.

Figure 15a and Figure 15b show more TIG welding when two SPL PL90_3 diodes are used but with slightly different angle. Figure 16a and Figure 16b show images of TIG welding on stainless steel and mild steel when three laser diodes are used. As can be seen from all the images shown below, weld arc is totally eliminated and the weld pool area is clear and the information that can be extracted for welding process control are in abundance due to the absence of the arc light. The results obtained demonstrate the potential and the effectiveness of the laser diode as an illumination source for monitoring arc welding. The attributes and low cost of the laser diode makes an attractive option compared to the bulky and expensive illumination systems.

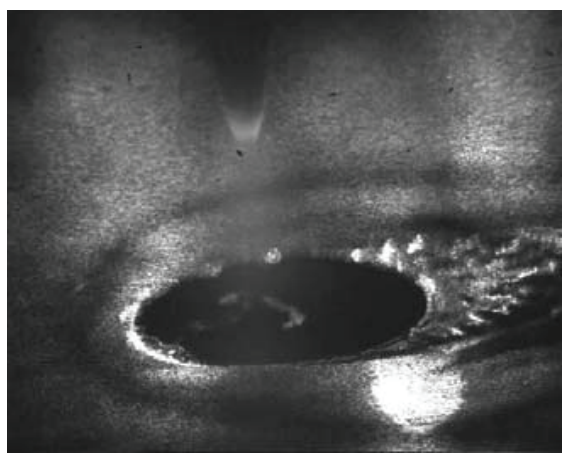

a. $80 \mathrm{~A}, 5$ us exposure time, forward reflection

Fig. 12. TIG welding on stainless steel, type 1

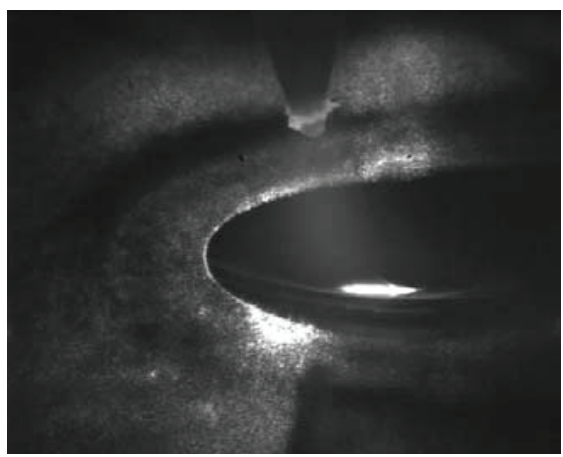

a. $100 \mathrm{~A}, 5$ us exposure time, forward reflection

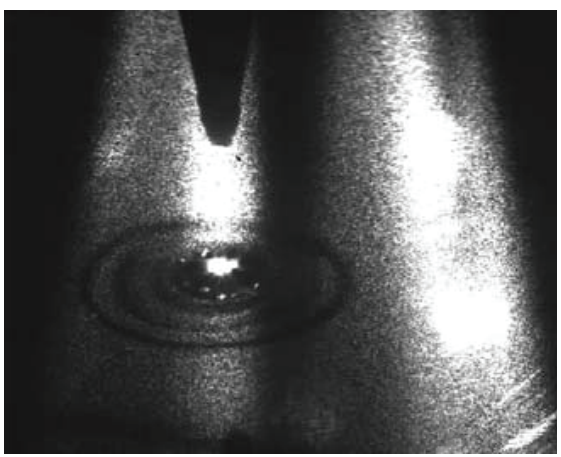

b. $50 \mathrm{~A}, 5$ us exposure time, forward reflection

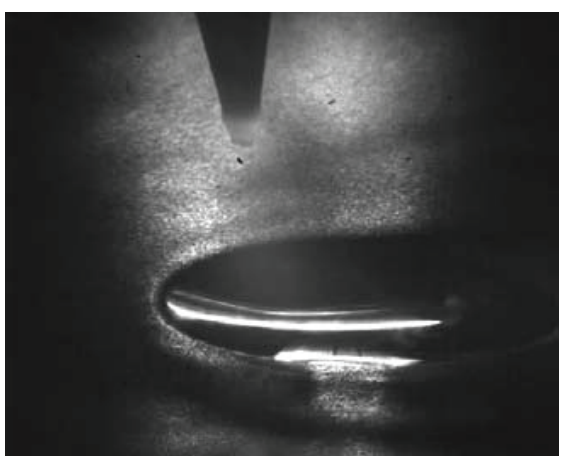

b. $80 \mathrm{~A}, 5$ us exposure time, forward reflection

Fig. 13. TIG welding on stainless steel, type 2 

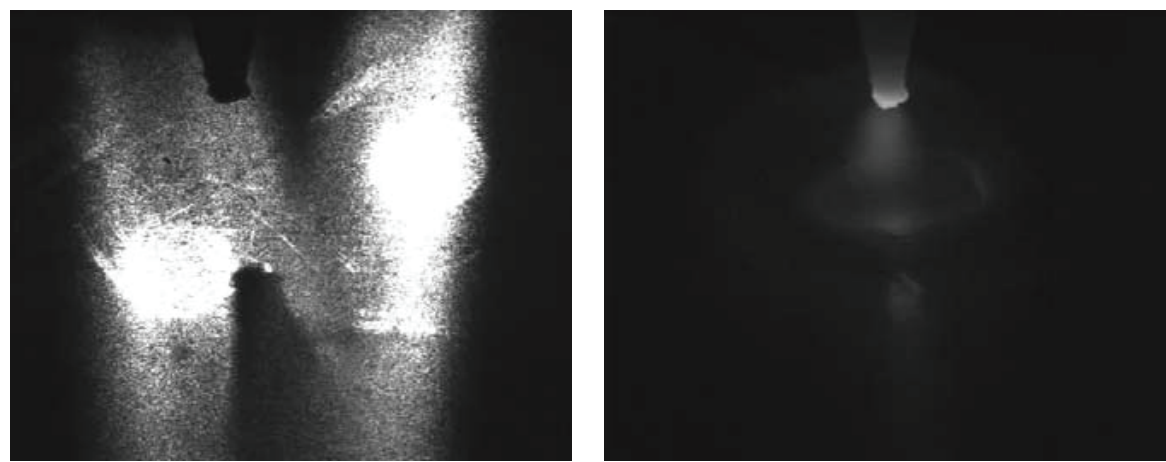

a. Illumination from two laser diodes, $50 \mathrm{~A}$ b. Arc light is totally cut off by spectral and temporal filtering, no illumination used, $50 \mathrm{~A}$
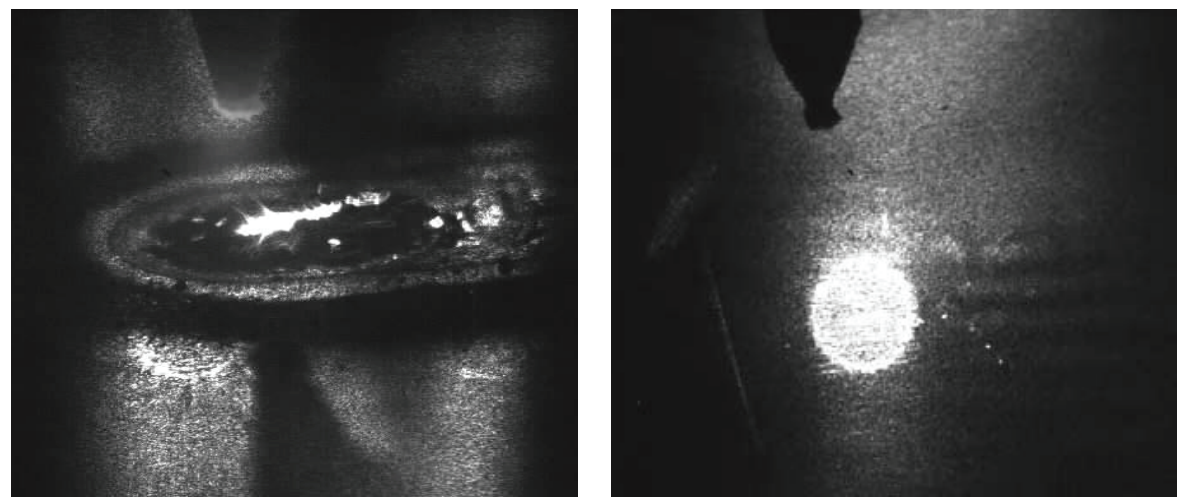

c. Illumination from two laser diodes, $80 \mathrm{~A}$

d. Illumination from one laser diode, $50 \mathrm{~A}$

Fig. 14. TIG welding, uneven light distribution

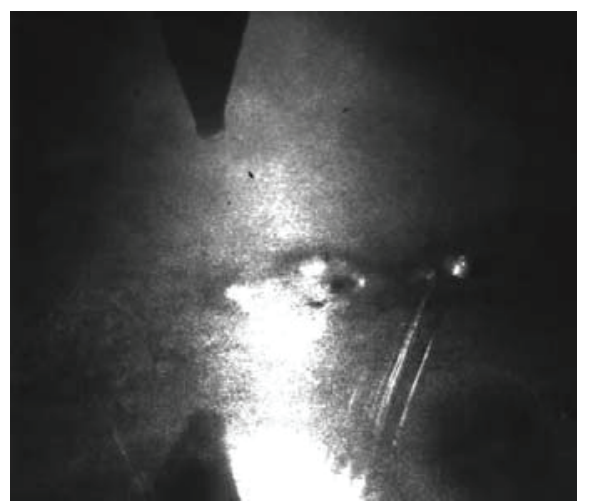

a. $50 \mathrm{~A}$

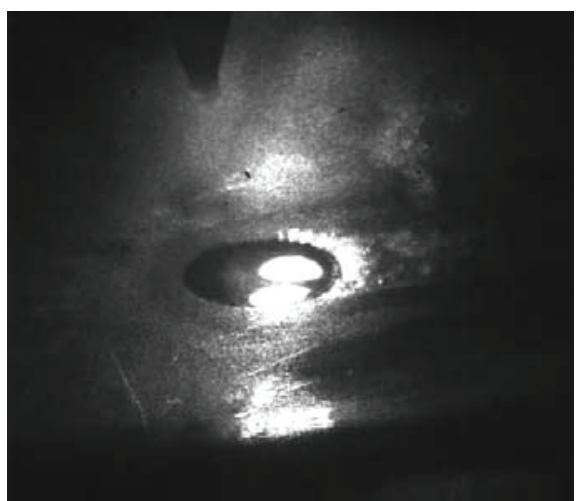

b. $100 \mathrm{~A}$

Fig. 15. TIG welding, different angle, type 1 


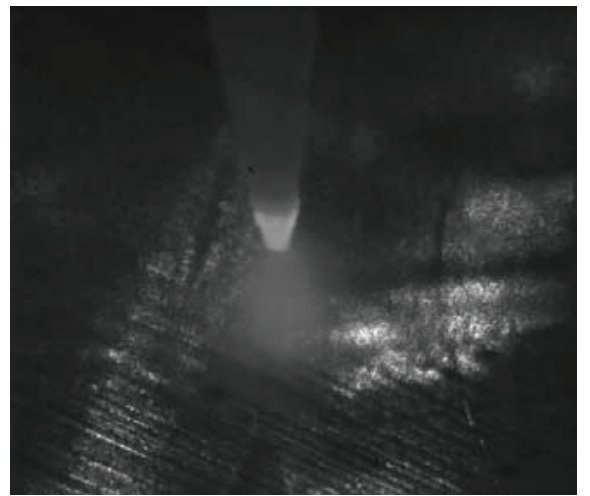

a. TIG welding on mildsteel, $124 \mathrm{~A}$

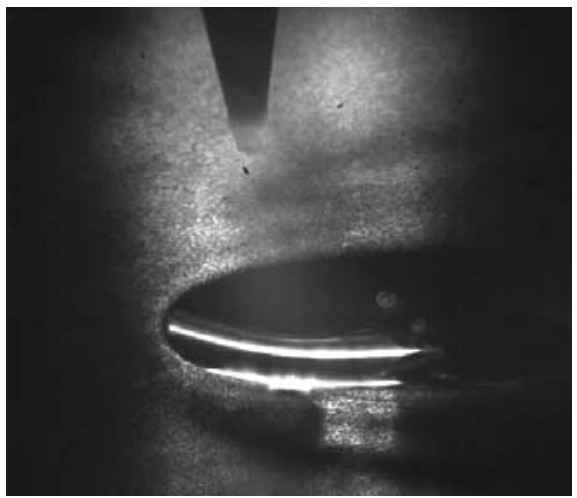

b. TIG weldign on stainless steel, $80 \mathrm{~A}$

Fig. 16. TIG welding, better angle, better light distribution, 3 laser diodes, type 1

\section{Conclusion and future work}

In this study a novel low cost vision system has been developed to image the topside of the weld pool. The vision system described has been shown to effectively remove arc light and produce reliable and high quality real-time welding images. The system incorporates a CMOS camera, a laser diode based illumination source, a lens and a narrow band pass filter. The system was tested by conducting some TIG welding trials on stainless steel and mild steel and employing only one, two and three laser diodes at a time. Some of the images obtained are included in this chapter.

Arc light is extremely intense that it is impossible to see through the arc to the weld pool, so for effective viewing the arc light must be reduced or even eliminated. The selection of the specific wavelength at which the illumination source and the band pass filter will be based on is a crucial aspect for blocking the arc light and providing a high quality weld pool image. It was found that arc light radiations are dependent on the shielding gas and work piece material as well as the current levels. TIG welding experimental results obtained show that the spectral distribution of arc light is at a minimum level in the infrared region. Hence, operating at the infrared region seems to be the ideal case so that a low power illumination source can be used. However, operating at this region would require an infrared camera and an infrared illumination source and this option would be commercially unattractive. Therefore, an optimum operating wavelength has been chosen based on the welding spectra obtained and taking into consideration the limitations of both the camera and the illumination source. This wavelength or spectral window where the camera will have the least disturbance from welding arc emissions was found to be between around 800nm $950 \mathrm{~nm}$. Improved images with relatively low power illumination source were obtained at this spectral window.

The illumination achieved by using laser diodes has proved very successful. This is the first time that laser diodes are used as an illumination source for weld pool monitoring. Experiments were carried out with just a few diodes to produce sufficient power to illuminate the weld pool. More diodes and better beam delivery to the weld scene would increase the quality of the images dramatically. For example, the use of 10 laser diodes 
would produce a peak power output in the range of $750 \mathrm{~W}-900 \mathrm{~W}$ at a low cost of under $£ 150$. This is a major achievement and would surely revolutionise the illumination industry since its output power is comparable to that of laser illumination but it is much more affordable and economical as a commercial system. The cost of a laser system is in the range of $£ 10 \mathrm{~K}$ and above, but the cost of this laser diode system is very small (less than $£ 100$ ). More work is required on the delivery of the power onto the weld area. Beam delivery could either be fibre coupling or focussing optics. This would be required when a large number of laser diodes are used. However, a system such as the one developed in this research project which uses only a few laser diodes does not suffer from power loss due to the short distance from the illumination source to the work piece. The developed vision system is compact and light and can therefore be situated near the work piece without the need for a beam delivery method.

In general, laser diodes are a lot more powerful than LEDs. Laser diodes can be driven with more current and hence an increased output power. For example the Osram SPL PL90_3 can be pulsed with a maximum pulse current of $40 \mathrm{~A}$, which produces a peak power of up to 90W. Whereas, LEDs can only be pulsed at currents much less than $40 \mathrm{~A}$ and can only produce a few watts. Laser diodes can be pulsed at very short pulse widths typically around 40ns - 100ns. The pulse width can be increased to around 10us as long as the duty cycle is kept low and lower currents are used. Meanwhile, LEDs have a much longer pulse width, typically around 100us. Since laser diodes can be pulsed at shorter pulse widths, they can be overdriven to obtain more power as long as the duty cycle is not exceeded. Although high power, super-radiant and high flux LEDs are widely available, the power output is still low for weld pool monitoring. It can be concluded that due to several factors such as, emission pattern, spectral width and pulse width limitations, it is unlikely that LEDs will be the illumination source for such applications in the near future. LEDs have wide spectral width, wide emission pattern and inadequate pulsing capabilities as well as low power outputs compared to laser diodes. Therefore, the low cost laser diode illumination system developed is an extremely efficient and economic alternative illumination system to the bulky and expensive laser systems usually adopted.

\section{Acknowledgment}

This project is supported by the Deanship of Scientific Research of King Fahd University of Petroleum and Minerals under project number JF090016. Part of this work was conducted at the Electrical Engineering Department, University of Liverpool, UK.

\section{References}

Allende, G.; Mirapeix, J.; Cobdo, A.; Conde, O. M. \& Lopez-Higuera, J. M. (2008). Arc welding quality monitoring by means of near infrared imaging spectroscopy. Society of Photo-Optical Instrumentation Engineers, ISBN 978-0-8194-7130-7, 18-20, Orlando, Florida, USA, March 2008

Ancona, A.; Lugara, P. M.; Ottonelli, F. \& Catalano, I. M. (2004). A sensing torch for on-line monitoring of gas tungsten arc welding processes of steel pipes. IOP Publishing, Mea. Sci. Technol., Vol. 15, pp 2412-2418 
Anderson, P. C. J. (1997). A review of sensor systems for the top face control of weld penetration. The TWI Journal, Vol. 6, No 4, pp 654-697

Arata, Y.; Inoue, K.; Fuatama M. \& Oh, T. (1980). Investigation of Welding Arc Sound. Transactions of JWRI, Vol. 9, pp 25-30

Bae, K. Y.; Lee, T. H. \& Ahn, K. C. (2002). An optical sensing system for seam tracking and weld pool control in gas metal arc welding of steel pipe. Journal of Materials Processing Technology, Vol. 120, pp 458-465

Baik, S. H.; Kim, M. S.; Park, S. K.; Chung, C. M.; Kim, C. J. \& Kim, K. J. (2000). Process monitoring of laser welding using chromatic filtering of thermal radiation. IOP Publishing, Meas. Sci. Technology, Vol. 11, pp 1772-1777

Balfour, C.; Lucas, J. Maqbool, S.; Smith, J. S. \& Mcilroy, L. (2000). A Neural Network Model for MIG welding Parameter Prediction. Proc. 10th Int. Conf. on Computer Technology in Welding, Copenhagen, Denmark

Boughton, P.; Rider, G. \& Smith, C. J. (1978). Feedback Control of Penetration in 1978. Advances in Welding Processes, The Welding Institute, Cambridge, England, pp 203309

Chen, S. B.; Zhang, Y.; Qiu, T. \& Lin, T. (2000). Robotic welding systems with vision sensing and self learning neuron control of arc welding processes. Journal of Intelligent and Robotic Systems, Vol. 36, pp 191-208

Chin, B A.; Madsen, N. H. \& Goodling, J. S. (1983). Infrared Thermography for Sensing the Arc Welding Process. Welding Journal, Vol. 62, pp 227-234

Du, J.; Longobardi, J.; Latham, W. P. \& Kar, A. (2000). Welding geometry and tensile strength in laser thin sheet metals. Science and Technology of Welding and Joining, Vol. 5, No. 5, pp. 304-309, October 2000

Farson, D.; Richardson R. W. \& Li, X. (1998). Infrared measurement of base metal temperature in gas tungsten arc welding. WJ supplement, AWS

Frazer, I.; Fyffe, L.; Gibson, O. J. \& Lucas, W. (2002). Remotely operated underwater thermal cutting processes for decommissioning of large North Sea platforms. Proc. of $O M A E, 21$ st International Conf. on offshore Mechanics and Artic Engineering, Norway, June 2002

Futamata, M. (1983). Applications of arc sound for detection of welding process. Journal of the Japan welding society, Vol. 1, No. 1, pp 11-15

Hong, L.; kee, L. F. M.; Yu, J. W. J.; Mohanamurthy, P. H.; Devanathan, R.; Xiaoqi, C. \& Piu, C. S. (2000). Vision based GTA weld pool sensing and control using neurofuzzy logic. SIMTech Technical Report (AT/00/011/AMP). Singapore Institute of Manufacturing Technology

Huang, W. \& Kovacevic, R. W. (2009). Feasibility study of using acoustic signals for online monitoring of the depth of weld in the laser welding of high-strength steels. Proc. IMechE Vol. 223 Part B: J. Engineering Manufacture

Kovacevic, P.; Zhang, Y. M. \& Li, L.(1996). Monitoring of weld joint penetration based on weld pool geometrical appearance. Welding Journal, Vol. 75, No. 10, pp 317-329

Li, P. J. \& Zhang, Y. M. (2000) Analysis of an Arc Light Mechanism and its Applications in Sensing of the GTAW Process", Welding Research Supplement, Research and Development, pp 252-260, September 2000 
Luo, H.; Devanathan, R.; Wang, J.; Chen, X. \& Sun, Z. (2002). Vision based Neurofuzzy logic control of weld pool geometry. Sci. and Tech. of Welding and Joining, Vol. 7, No. 5, pp321-325

Madigan, R. B.; Quinn, T. B. \& Siewert, T. A. (1989) Sensing Droplet Detachment and Electrode Extension for Control of Gas Metal Arc Welding. Proceedings of the 2nd International Conference on Trends in Welding Research, pp 999-1002, Gatlinburg, Tenn, 1989

Miller, M.; Mi, B; Kita, A. \& Ume, I. C. (2002). Development of automated real-time data acquisition system for robotic weld quality monitoring. Mechatronics, Vol. 12, pp 1259-1269

Pal, K.; Bhattacharya, S. \& Pal, S. (2010). Investigation on arc sound and metal transfer modes for on-line monitoring in pulsed gas metal arc welding. Journal of Materials Processing Technology, Volume 210, Issue 10, Pages 1397-1410.

Richardson, R. W. \& Edwards, F. S. (1995) Controlling GT arc length from arc light emissions. Proceedings of the 4th Trends in Welding Research, Gatlinburg, Tenn, Vol. 6, pp 715-720, 1995.

Richardson, R. W.; Gutow, D. A. \& Rao, S. H. (1982). A Vision Based System for Arc Weld Pool Size Control. Measurement and Control for Batch Manufacturing, The American Society of Mechanical Engineers, New York, pp 65-75

Sforza, P. \& de Blasiis, D. (2002). On-line optical monitoring system for arc welding", NDTEE International, Vol. 35, pp 37-43, 2002

Sibillano, T.; Ancona, A.; Berardi, V. \& Lugarà, P. M. (2009). A Real-Time Spectroscopic Sensor for Monitoring Laser Welding Processes. Sensors Review, 9, 3376-3385; doi:10.3390/s90503376, 2009

Song, H. S. \& Zhang, Y. M. (2008). Measurement and Analysis of Three-Dimensional Specular Gas Tungsten Arc Weld Pool Surface. Supplement to The Welding Journal, pages 85-95, April 2008

Sorensen, C. D. \& Eagar, T. W. (1990) Measurement of oscillations in partially penetrated weld pools through spectral analysis. Journal of Dynamic Systems, Measurement and Control, Transactions ASME, Vol. 112, No. 9, pp 463, September 1990

Sun, Z.; Chen, Q.; Zhang, W.; Cao, Y. \& Liu, P. (2006). A novel visual image sensor for CO2 short circuiting arc welding and its applications in weld reinforcement detection. IOP Publishing, Mea. Sci. Technol., Vol. 17, pp 3212-3220

Węglowski, M. S. (2009). Measurement of Arc Light Spectrum in the MAG Welding Method. Institute of Welding , Błogostawionego Czestawa 16/18, 44-100 Gliwice , Poland

Wikle, H. C. \& Kottingam, S. (2001). Infrared sensing techniques for penetration depth control of the submerged arc welding processes, Journal of materials processing technology, Vol. 113, pp 228-233

Wu, C. S.; Gao, J. Q.; Liu, X. F. \& Zhao, Y. H. (2003). Vision-based measurement of weld pool geometry in constant-current gas tungsten arc welding. Proc. Instn. Mech. Engrs, Vol. 217, Part B, J. Engineering Manufacture

Wu, C. S.; Polte, T. \& Rehfeldt, D. (2000). Gas metal arc welding monitoring and quality evaluation using neural network. Science and Technology of Welding and Joining, Vol. 5, No. 5, 2000, Vol. 38, pp 131-141. 
Zackenhouse, M. \& Hrdt, D. E. (1983). Weld Pool Impedance Identification for Size Measurement and Control. ASME Journal of Dynamic Systems, Measurement and Control, Vol. 105, pp179-184, 1983

Zhang, P.; Kong, L; Wenzhong, L, Jingjing, C \& Zhou, K. (2008). Real-time Monitoring of Laser Welding Based on Multiple Sensors. Control and Decision Conference, CCDC, page 1746-1748, China, July 2008

Zhang, Y. M.; Kovacevic, R. W. \& Li, L. (1996). Characterisation and real-time measurement of geometrical appearance of the weld pool. Int. J. Mach. Tools Manufact., Vol. 36, No. 7, pp. 799-816 


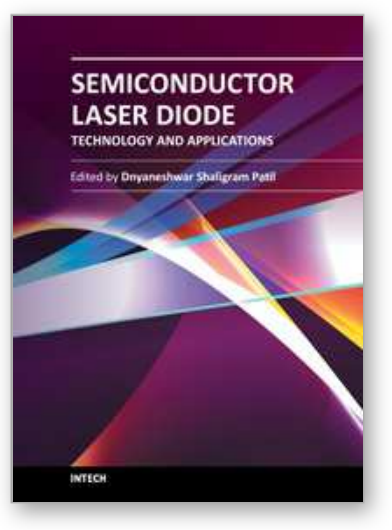

\author{
Semiconductor Laser Diode Technology and Applications \\ Edited by Dr. Dnyaneshwar Shaligram Patil
}

ISBN 978-953-51-0549-7

Hard cover, 376 pages

Publisher InTech

Published online 25, April, 2012

Published in print edition April, 2012

This book represents a unique collection of the latest developments in the rapidly developing world of semiconductor laser diode technology and applications. An international group of distinguished contributors have covered particular aspects and the book includes optimization of semiconductor laser diode parameters for fascinating applications. This collection of chapters will be of considerable interest to engineers, scientists, technologists and physicists working in research and development in the field of semiconductor laser diode, as well as to young researchers who are at the beginning of their career.

\title{
How to reference
}

In order to correctly reference this scholarly work, feel free to copy and paste the following:

Badr M. Abdullah (2012). Monitoring of Welding Using Laser Diodes, Semiconductor Laser Diode Technology and Applications, Dr. Dnyaneshwar Shaligram Patil (Ed.), ISBN: 978-953-51-0549-7, InTech, Available from: http://www.intechopen.com/books/semiconductor-laser-diode-technology-and-applications/monitoring-ofwelding-using-laser-diodes

\section{INTECH}

open science | open minds

\section{InTech Europe}

University Campus STeP Ri

Slavka Krautzeka 83/A

51000 Rijeka, Croatia

Phone: +385 (51) 770447

Fax: +385 (51) 686166

www.intechopen.com

\section{InTech China}

Unit 405, Office Block, Hotel Equatorial Shanghai

No.65, Yan An Road (West), Shanghai, 200040, China

中国上海市延安西路65号上海国际贵都大饭店办公楼 405 单元

Phone: +86-21-62489820

Fax: $+86-21-62489821$ 
(C) 2012 The Author(s). Licensee IntechOpen. This is an open access article distributed under the terms of the Creative Commons Attribution 3.0 License, which permits unrestricted use, distribution, and reproduction in any medium, provided the original work is properly cited. 